was one of the many journals founded by Kropotkin, still appears as the official organ of anarchists - there can be few who would not acknowledge his service to humanity. The Doukhobor colony in British Columbia, for example, which to-day flourishes as an autonomous community, owes its escape from Tsarist persecution and its free existence jointly to Tolstoy and Kropotkin. Mahatma Gandhi, said to be Tolstoy's greatest disciple, was an enthusiastic reader of Kropotkin's unceasing flow of articles and based his idea of a society of village communes in India on Kropotkin's theories. In the twilight of his long life after triumphantly returning to Russia in 1917, following forty years of life in exile, Kropotkin tasted the bitterness of the Revolution which he had helped to promote. Yet, in his misery, his faith in man and progress was undimmed and led to the production of his well-known book on ethics in his seventy-seventh year. Of this book Herbert Read has justly said : "No better history of ethics has ever been written". Nor has a better biography than this been written of one who served his age so selflessly and mistakenly and who was described by Oscar Wilde "as one of the two men he had met who lived perfectly fulfilled lives".

T. H. HAWKINS

\section{GENETICS REVISED}

\section{Principles of Genetics}

By Prof. Edmund W. Sinnott, Prof. L. C. Dunn and Prof. Th. Dobzhansky. (McGraw-Hill Publications in the Botanical Sciences.) Fourth edition. Pp. xiv +505. (London: MeGraw-Hill Publishing Co., Ltd., 1950.) 42s. 6d.

$\mathrm{T}$ HE writing of a text-book of genetics presents a special difficulty. It is that the subject has advanced by a series of explosions which might have been expected to shatter whatever system or order had preceded them. The discovery. of Drosophila by Morgan and of the X-ray tube by Muller each put the subject on a new technical and theoretical basis; and after so many years we have still not exhausted the possibilities of studying either Morgan's recombination at meiosis or Muller's mutation at mitosis. Yet since these things happened we have had to absorb new systems of chromosome mechanics and chemistry, of micro-organismal genetics and cytoplasmic particles and of evolutionary and taxonomic analysis.

All these explosions have burst on us since the first edition of Sinnott and Dunn's "Principles of Genetics". It would not be surprising, therefore, if the fourth edition (although strengthened by the collaboration of Prof. Dobzhansky) were to show some signs of dislocation ; perhaps, indeed, it does. But the absence of stability in detail merely emphasizes the stability in principle. It is more refreshing than otherwise, and among much that has been rewritten, all students of natural variation and the origin of species will be glad to see their chromosome foundations and adaptive. properties so well described in the new edition.

There is, however, a second difficulty in writing about genetics, namely, that all those who have so far attempted to lay the subject before us have had some training in pre-genetic biology. It is only in the twenty-five years since this book first appeared that the position of the new discipline has become clear. Genetics, as we now see, is itself the frame- work of biology. It is simply the demonstration of the primary determinism of living organisms.

How is a writer on genetics to explain this position to students who, like himself, have been trained in what passes for biology in the formal pre-genetic or non-genetic curriculum ? The present work, having grown through many editions, cannot attempt this task. It does something different, however, which no one else has succeeded in doing so well. It patiently lays before the student the experimental foundations of the subject. It does so in a simple form with all the necessary technical and historical background, and it provides a wealth of pictorial illustration.

Every book on genetics at the present time is bound to be an experiment in trying out one or other of the hundred different ways of presenting the subject. The successful experiment will be the basis of future methods of teaching and also perhaps of research. The present work is not likely to be important in this direction. Rather it is to be looked upon as a step in the transition from the old biology to the new. It is a necessary step in which the new genetic methods of inquiry and their results are introduced gently to an audience which does not yet realize that the old foundations of botany, zoology and microbiology, are being undermined, and that the classical notions of evolution, species, individual, sexual reproduction, organism, disease and life are disintegrating under their eyes.

The reprinting as an appendix of the Royal Horticultural Society's translation of Mendel's original paper seems now to be particularly valuable. Those who read it again (especially the concluding remarks) will realize that Mendel's work was not wholly rediscovered in 1900 and will profit by the realization. They will also learn something of the process of discovery itself.

C. D. D.

\section{CLASSICAL INVESTIGATIONS OF THE PLASTIC PROPERTIES OF CRYSTALS}

Plasticity of Crystals

With Special Reference to Metals. By Dr. E. Schmid and Dr. W. Boas. A translation from the German by F. A. Hughes and Co., Ltd., of 'Kristallplastizität mit besonderer Berücksichtigung der Metalle'. Pp. xvi+353. (London: F. A. Hughes and Co., Ltd., 1950.) n.p.

T $\mathrm{T}$ is not surprising that a translation has been made of this well-established classic. What is surprising, at first thought, is why a translation has appeared now, and only now, some fifteen years after the original. The answer to this question reflects, in addition, of course, on the exceptional standard of the work, upon the way in which this branch of science is claiming the attention of an increasingly large audience, an audience of wider interests than the specialists who acclaimed the original publication.

Intensive research into the physies of the plasticity of crystals began around 1920 when the developments of X-ray crystal analysis and of methods for growing single crystals prepared the way for a systematic attack. During the following ten years or so a wide field was opened up. The crystallographic aspects of slipping, twinning and fracture were thoroughly studied, particularly in 